\title{
VOLATILITY-REDUCING BIODIVERSITY CONSERVATION UNDER STRATEGIC INTERACTIONS
}

\author{
EMMANUELLE AUGERAUD-VÉRON, GIORGIO FABBRI, \\ AND KATHELINE SCHUBERT
}

\begin{abstract}
How can decentralized individual decisions inefficiently reduce the ability of biodiversity to mitigate ecological and environmental variability and then its "natural insurance" role? In this article we present a simple theoretical set-up to address this question and to evaluate some policy options.

We study a model of strategic competition among farmers for the conversion of a natural forest to agricultural land. Unconverted forest land allows to conserve biodiversity, which contributes to reducing the volatility of agricultural production. Agents' utility is given in terms of a Kreps Porteus stochastic differential utility capable of disentangling risk aversion and aversion to fluctuations.

We characterize the land used by each farmer and her welfare at the Nash equilibrium, we evaluate the over-exploitation of the land and the agents' welfare loss compared to the socially optimal solution and we study the drivers of the inefficiencies of the decentralized equilibrium.

After characterizing the value of biodiversity in the model, we use it to obtain a decomposition which helps to study the policy implications of the model by identifying in which cases the allocation of property rights is preferable to the introduction of a tax on land conversion. Our results suggest that enforcing property rights is more relevant in case of stagnant economies while taxing land conversion may be more suited for rapidly developing economies.
\end{abstract}

KEY WORDS: Biodiversity, insurance value, land conversion, recursive preferences, stochastic differential games.

JEL CLASSIFICATION: Q56, Q58, Q10, Q15, O13, O20, C73, D62.

Date: July 8, 2021. 


\section{INTRODUCTION}

According to FAO (2018) projections, agricultural production is expected to increase by $70 \%$ between 2005 and 2050 to feed a population that is expected to reach 9.1 billion people by 2050 . Whereas part of this increase will come from higher agricultural yields, another part will inevitably require the extension of agricultural land (by 5\% per year, FAO, 2018), at the expense of natural ecosystems. This land conversion phenomenon is, and will be in the future, one of the main drivers of biodiversity destruction (IPBES, 2019).

The evaluation of the phenomenon demands to appraise the trade-off between agricultural production and the damages caused by biodiversity loss. It is part of a broader reflexion on the development of theoretical tools for identifying the economic value of biodiversity. Traditional approaches evaluate direct and indirect use values (see for instance Simpson et al., 1996, for the case of the pharmaceutical industry or Maille and Mendelsohn, 1993, for ecotourism) or, in a context of uncertainty, consider the option and quasi-option values of biodiversity (see e.g. Lasserre and Kassar, 2004, or Di Falco and Perrings, 2005).

A more recent stream of literature introduced and exploited the notion of insurance value of biodiversity. The idea comes from the recognition that a series of services offered by biodiversity have an impact on the variability of ecological and then economic conditions. It is the case, for example, with regulating services (control of the local climate, flood control, regulation of soil fertility, pollination, etc.) or biocontrol services (pest control, resistance to plant invasion, disease control, etc.). In a series of contributions Baumgärtner (2007), Quaas et al. (2007), Quaas and Baumgärtner (2008), Baumgärtner and Quaas (2010) and Baumgärtner and Strunz (2014) measured the insurance value as the reduction of the risk premium that can be achieved by relying on conservative ecosystem management. Augeraud-Véron et al. (2019) ${ }^{1}$ analyzed the total value of biodiversity as the welfare gain that can be attributed to biodiversity conservation in a dynamic framework, distinguishing between the notion of risk and the notion of intertemporal substitutability. That study also highlighted the insurance value of biodiversity in a dynamic set-up.

\footnotetext{
${ }^{1}$ See also Quaas et al. (2019) for a similar argument applied to a model with natural capital.
} 
However, studying the optimal trade-off between agricultural production and biodiversity conservation is not enough. As various external effects are involved, the study of the decentralized solution is also necessary. Indeed, even if in some countries the number of farmers is decreasing, agriculture remains a highly distributed activity, for which farmers' productive choices act as an externality on the outcomes of others.

We study in this paper the case of a forest-rich developing economy needing to decide how much forest to be converted to agriculture and how much to be kept undeveloped, for biodiversity conservation. Among the many motives a country could have for conserving biodiversity we choose to investigate the natural insurance against fluctuations of agricultural productivity motive. The stabilizing role of biodiversity has been largely documented and the ecological mechanisms behind this phenomenon are well understood (see for instance Loreau and Mazancourt, 2013). The role of common pool resources such as natural forests as an insurance device for rural poor is also well documented (Baland and Francois, 2005, Delacote, 2009), in a context where they do not have access to formal insurance and to credit markets (Banerjee and Duflo, 2010).

In this spirit we develop and study a decentralized model where two farmers ${ }^{2}$ can obtain property rights on an undeveloped land, for instance a natural forest. Each farmer chooses the share of her land she converts to agriculture, then produces and consumes the harvest from her plot. The evolution of agricultural productivity over time is influenced by the endogenous choices about the size of the plots. Indeed, the part of land which is not used for farming is devoted to biodiversity conservation and the services provided by biodiversity reduce the volatility of agricultural productivity. The two farmers/players coordinate on a Nash equilibrium of the economy.

Noack et al. (2019) provides a nice illustration of the relevance of our model. The authors use panel data covering 7,556 households in 23 developing countries, combined with data on droughts, the major environmental reason for crop losses, data on natural biodiversity and data on the timing of the agricultural cycle. The intrinsic volatility of agricultural yields comes from weather events, here droughts, whereas natural biodiversity has a stabilizing role. One of Noack et al. (2019)'s results is that the negative impact of droughts on crop income declines

\footnotetext{
${ }^{2}$ The results for the $n$-farmer case are also provided, see Section 6 .
} 
when natural biodiversity increases. They are able to estimate the magnitude of the effect and obtain that reducing biodiversity by one standard deviation below the regional mean almost doubles the negative impact of droughts on income.

In this context the attitudes of farmer towards income intertemporal fluctuations and towards risk are essential. In order to disentangle aversion to fluctuations and aversion to risk we use a recursive utility set-up, initially introduced in the seminal works of Epstein and Zin (1991) and of Duffie and Epstein (1992). The relevance of recursive utilities in natural resources and environmental economic models is well documented (see for instance Knapp and Olson, 1996, Epaulard and Pommeret, 2003 or Howitt et al., 2005) but this is, as far as we know, the first work where a dynamic environmental economic model with strategic interaction and Epstein-Zin preferences is studied and solved.

The model is completely solved by explicitly finding the Nash equilibrium of the differential game and characterizing for each farmer the share of land used for agricultural activities. These shares are constant over time. For any farmer, impatience drives land conversion, whereas risk and its perception play in the opposite direction. What the other farmer does also plays a role: a farmer will convert more land to farming when the other farmer does so if her aversion to fluctuations is smaller than unity, and she will convert less land when the other farmer converts more if her aversion to fluctuations is high.

We then compare, in the symmetric situation with uniform preference and technology parameters, the equilibrium in the strategic competition set-up and the socially optimal choice. As expected, since the agents only partly internalize the negative effects of their actions, an over-exploitation of the forest systematically arises, so that the land available for biodiversity conservation is always lower in the decentralized case than at the social optimum.

We proceed with welfare comparisons and some policy implications of our results. We show how to decompose the per-capita welfare gain from biodiversity conservation in two parts: the welfare gain of moving from the open access equilibrium to the Nash equilibrium, and the welfare gain of moving from the Nash equilibrium to the optimum. Depending on which of the two is prevalent we can identify in which cases the allocation of property rights is preferable to the introduction of a land conversion tax. In particular we show that enforcing property 
rights is more relevant in case of stagnant technological progress in agricultural activities while policies consisting in pricing the volatility externality (for instance through a tax on land conversion) may be more suited for rapidly developing economies averse to fluctuations.

Finally we extend our result to the more general case of more than 2 farmers. We show that the more farmers there are the larger land conversion and the bigger the volatility externality. Moreover, if the aversion to fluctuations is less than unity, when the number of farmers increases every individual share of land devoted to farming increases as well. In this sense, a small aversion to fluctuations is detrimental to biodiversity conservation. Conversely, if farmers have a large aversion to fluctuations, when the number of farmers increases each of them converts less land. The pressure of an increasing population on a fixed land area may then either cause a race to land conversion detrimental to biodiversity conservation, or a reduction of each farmer's plot mitigating biodiversity destruction, depending on their aversion to fluctuations.

The paper proceeds as follows. In Section 2 we present the main elements of the model which is completely solved in Section 3. Section 4 is devoted to the comparison between the two-players setting and the social optimum benchmark while in Section 5 we discuss the policy hints that we get from the model. In Section 6 we look at the results for the $n$-player extension of the model and in Section 7 we conclude. The appendices contain technical details and the proofs of all the results. 
2. THE MODEL

We develop and study a decentralized version of the model proposed by Augeraud-Véron et al. (2019).

We consider an agricultural economy with a stock $L=1$ of land, initially undeveloped - for instance a natural forest. This forest shelters biodiversity, which is a common pool resource. Several farmers contemplate converting the forest to agricultural land. Each one can obtain from the state property rights on a plot, and then has to decide how much of his plot to convert to farming ${ }^{3}$. The forest left intact supports biodiversity and provides ecosystem services.

As explained in Augeraud-Véron et al. (2019), there is a close link between biodiversity and space, synthesized in the classical species-area curve, initially introduced by Arrhenius (1921) and Gleason (1922) and well anchored in the ecological literature. According to the species-area curve, the long term species richness $S(t)$ is constrained by the size of the natural habitat $1-f(t)$. The relationship is non-linear and specific to any ecological and geographical context. A widespread empirically-based specification is the power function used fo instance by Brook et al., (2003) and Storch et al. (2012):

$$
S(t)=\epsilon_{1}(1-f(t))^{\epsilon_{2}} \quad \text { with } \quad \epsilon_{1}>0 \quad \text { and } \quad 0<\epsilon_{2}<1
$$

Then, the evolution of biodiversity $B(t)$, defined as the variety of ecological elements present in the habitat, including genes, species, functional traits, communities etc., can be modeled as:

$$
\eta \dot{B}(t)=-(B(t)-S(t)) \quad \text { with } \quad \eta \geq 0
$$

where $\eta$ the relaxation time of biodiversity (see Lafuite and Loreau, 2017). When this relaxation time is negligible, biodiversity takes instantaneously its long term value, that is $B(t)=S(t)$, meaning that it responds instantaneously to habitat conversion.

We describe here a 2-player setting: ${ }^{4}$ we suppose that 2 players/farmers can appropriate the forest for farming purposes. They are indexed by $i \in\{1,2\}$.

\footnotetext{
${ }^{3}$ We will contrast in Subsection 5.2 this institutional setting where farmers can obtain property rights on the forest to the case where the forest remains in open access, meaning that there is no incentive for the farmers to refrain from converting all of it to farming.

${ }^{4}$ The $n$-player extension is discussed in Section 6.
} 
Farmer $i$ can appropriate some share $f_{i}(t)$ of total land, although the following constraint needs to be verified:

$$
f_{1}(t)+f_{2}(t) \leq 1, \quad t \geq 0
$$

We denote by $f(t):=f_{1}(t)+f_{2}(t) \in[0,1]$ and $1-f(t) \in[0,1]$ the shares of land respectively used for farming and left undeveloped, that is devoted to biodiversity conservation. We assume that the agricultural production output of farmer $i$ at time $t$ is given by:

$$
Y_{i}(t)=f_{i}(t) A_{i}(t)
$$

where $A_{i}(t)$ is the productivity ${ }^{5}$ of a unit of land farmed by agent $i$ at time $t$, whose dynamics is described by the following stochastic differential equation:

$$
\left\{\begin{array}{l}
\mathrm{d} A_{i}(t)=\alpha_{i} A_{i}(t) \mathrm{d} t+\sigma_{i} f(t)^{1 / 2} A_{i}(t) \mathrm{d} W(t) \\
A_{i}(0)=A_{i}^{0}
\end{array}\right.
$$

where $W$ is a real standard Brownian motion $W:[0,+\infty) \times \Omega \rightarrow \mathbb{R}$, adapted to some filtration $\mathcal{F}_{t}$, defined on a complete probability space $(\Omega, \mathcal{F}, \mathbb{P})$. In such an expression, $\alpha_{i} \in \mathbb{R}$ represents some fixed and exogenous rate of technological progress in farming activities (it can be equal to 0 ), and the term $\sigma_{i} f(t)^{1 / 2}$ measures the volatility of agricultural productivity. Total volatility has an exogenous component $\sigma_{i}$, stemming for instance from weather events, and an endogenous component $f(t)^{1 / 2}$, common to both farmers, increasing in the total share of land converted to agriculture, that is decreasing in the biodiversity level. ${ }^{6}$ It is in this sense that biodiversity appears in the model as insurance against adverse outcomes.

The two farmers play a non-cooperative game with Markovian strategies so that farmer $i$ chooses the size of land to cultivate in the form $f_{i}=\Psi_{i}\left(A_{1}, A_{2}\right)$

\footnotetext{
${ }^{5}$ An intense debate has developed, following the Green et al. (2005) contribution, on the importance of preserving biodiversity also in the context of land used for agriculture, in particular in relation to different farming practices (extensive vs intensive land use). The discussion about land sparing vs land sharing remains alive (see for instance Fisher et al., 2014, Kremen, 2015 or Renwick and Schellhorn, 2016). In the simplified context of the model presented here we abstract from this issue and we consider only an average productivity whose growth is exogenous and independent of the level of biodiversity.

${ }^{6}$ Augeraud-Véron et al. (2019) write more generally this endogenous component as: $f(t)^{\chi / 2}$, $\chi \geq 1$. We restrict ourselves to the case $\chi=1$ for simplicity, without loss of generality.
} 
where $\Psi_{i}: \mathbb{R}_{+}^{2} \rightarrow[0,1]$ is a measurable function. A couple of Markov strategies $\Psi:=\left(\Psi_{1}, \Psi_{2}\right)$ is admissible if (1) is verified for all positive couple of real numbers $\left(A_{1}, A_{2}\right)$, i.e. if

$$
\Psi_{1}\left(A_{1}, A_{2}\right)+\Psi_{2}\left(A_{1}, A_{2}\right) \leq 1, \text { for all }\left(A_{1}, A_{2}\right) \in \mathbb{R}_{+}^{2}
$$

and if the two equations (3) have a unique solution. ${ }^{7}$ We denote by $\mathcal{C}$ the set of admissible strategy couples:

$\mathcal{C}:=\left\{\Psi:=\left(\Psi_{1}, \Psi_{2}\right): \mathbb{R}_{+}^{2} \rightarrow[0,1]^{2}\right.$ measurable $: \Psi$ is an admissible strategy couple $\}$

Given a strategy $\Psi_{1}$ of Player 1 (respectively $\Psi_{2}$ of Player 2), we denote by $\mathcal{C}_{2}\left(\Psi_{1}\right)$ (respectively $\mathcal{C}_{1}\left(\Psi_{2}\right)$ ) the set

$$
\mathcal{C}_{2}\left(\Psi_{1}\right):=\left\{\Phi: \mathbb{R}_{+} \rightarrow[0,1] \text { measurable }:\left(\Psi_{1}, \Phi\right) \in \mathcal{C}\right\}
$$

(and similarly for $\mathcal{C}_{1}\left(\Psi_{2}\right)$ ).

We suppose that at each time $t \geq 0$ all the production is consumed:

$$
C_{i}(t)=Y_{i}(t)
$$

Farmer $i$ 's target is to maximize an infinite horizon, continuous time, EpsteinZin-Weil utility function with Kreps Porteus utility. This specification of utilities makes it possible to disentangle the notions of aversion to risk and aversion to fluctuations which are identified (and conflated) in the usual time additive expected utility function i.e. in the specifications where the target can be written as the expected value of utility on each trajectory. We denote by $\theta_{i}>0$ (and $\left.\theta_{i} \neq 1\right)$ the (constant) relative risk aversion of Player $i$ and by $\phi_{i}>0$ her aversion to fluctuations i.e. the inverse of her intertemporal elasticity of substitution. The case $\theta_{i}=\phi_{i}$ corresponds to the usual time additive case. The discount rate of Player $i$ is denoted by $\rho_{i}>0$.

The standard additive case is sometime called "separable case" since the utility of agents can be written as the integral over time of the discounted instantaneous expected utility (so the time and the probability are somehow separated in two different integrals). The same thing cannot be done in context of recursive utility

\footnotetext{
${ }^{7}$ This second requirement is not very strong: the term $f$ is bounded (by 0 and 1 ) so the system of equations for $A$ has always linear growth, so that, by standard existence and uniqueness results for the solution of a system of SDE (see Chapter V of Protter, 2005), we only need to have weak Lipschitz-type continuity in the diffusion term (w.r.t. of $A_{i}$ ) and some mild regularity of $\Psi$ to guarantee the existence and the uniqueness of the solution.
} 
(as, for instance in the case of Epstein-Zin-Weil preferences that we use here). In this case the utility is expressed through the evolution of a suitable stochastic differential equation as more formally explained at the beginning of Appendix A. The interested reader can look at the foundational works by Duffie and Epstein (1992a, 1992b) and Duffie and Lions (1992) and at the more recent papers by Lazrak and Quenez (2003) or Kraft and Seifried (2014).

In this framework the problem focuses on the study of a pair of HamiltonJacobi-Bellman (HJB) equations of the following form:

$$
\begin{aligned}
& \rho_{i} \frac{1-\theta_{i}}{1-\phi_{i}} V_{i}\left(A_{1}, A_{2}\right)=\max _{f_{i} \in\left[0,1-f_{j}\right]}\left[\frac{\left(f_{i} A_{i}\right)^{1-\phi_{i}}}{1-\phi_{i}} \frac{1}{\left(\left(1-\theta_{i}\right) V_{i}\left(A_{1}, A_{2}\right)\right)^{\frac{1-\phi_{i}}{1-\theta_{i}}-1}}+\right. \\
&\left.\frac{\partial V_{i}}{\partial A_{1}} A_{1} \alpha_{1}+\frac{\partial V_{i}}{\partial A_{2}} A_{2} \alpha_{2}+\frac{1}{2}\left(f_{1}+f_{2}\right)\left\langle\left(\begin{array}{c}
\sigma_{1} \\
\sigma_{2}
\end{array}\right), H V_{i}\left(\begin{array}{c}
\sigma_{1} \\
\sigma_{2}
\end{array}\right)\right\rangle\right]
\end{aligned}
$$

where $V_{i}\left(A_{1}, A_{2}\right)$ is the value function of Player $i, H V_{i}$ the Hessian matrix of $V_{i}$ and $\langle\cdot, \cdot\rangle$ the scalar product on $\mathbb{R}^{2}$ (we did not write explicitely the dependence of $\frac{\partial V_{i}}{\partial A_{1}}$ and $H V_{i}$ on $\left(A_{1}, A_{2}\right)$ to lighten the notation).

In this setting we implicitly make the assumption that the choice of developing land made by a farmer at any date is completely reversible. However, given the particular structure of the model, introducing an irreversibility constraint (i.e., in formal term, admitting only weakly increasing paths of the shares of land used for farming) would not significantly change the situation. Indeed the best strategies we identify are constant over time, so they remain so if we restrict the set of possible choices.

More technical details on the formulation we use can be found in Appendix A. The study of the HJB equations is carried out in Appendix B.

\section{THE CHARACTERIZATION OF THE STRATEGIC INTERACTION EQUILIBRIUM}

In this section we solve the model and get an explicit description of the Nash equilibrium. Let's start by defining the quantity

$$
x_{i}=\frac{\rho_{i}-\alpha_{i}\left(1-\phi_{i}\right)}{\theta_{i} \frac{\sigma_{i}^{2}}{2}}, \quad \text { for } i=1,2 .
$$


that will be frequently used below ${ }^{8}$. The strategies of the two players to balance are described in the following theorem.

Theorem 3.1. Suppose that

$$
\rho_{i}>\left(1-\phi_{i}\right) \alpha_{i}, \quad \text { for } i=1,2
$$

(it implies in particular $x_{1}$ and $x_{2}$ positive),

$$
\phi_{1}+\phi_{2}>1
$$

and that the following transversality condition is verified:

$$
\rho_{i}>\left(1-\theta_{i}\right)\left(\alpha_{i}-\theta_{i} \frac{\sigma_{i}^{2}}{2} \frac{x_{1}+x_{2}}{\phi_{1}+\phi_{2}-1}\right), \quad \text { for } i=1,2 .
$$

Then, if

$$
\bar{f}_{1}:=\frac{\phi_{2} x_{1}+\left(1-\phi_{1}\right) x_{2}}{\phi_{1}+\phi_{2}-1} \in(0,1)
$$

and

$$
\bar{f}_{2}:=\frac{\phi_{1} x_{2}+\left(1-\phi_{2}\right) x_{1}}{\phi_{1}+\phi_{2}-1} \in\left(0,1-\bar{f}_{1}\right)
$$

the couple

$$
\Psi_{2}\left(A_{1}, A_{2}\right) \equiv \bar{f}_{2}, \quad \Psi_{1}\left(A_{1}, A_{2}\right) \equiv \bar{f}_{1}
$$

is a Nash equilibrium of Markov strategies. Moreover it is the unique Nash equilibrium of Markov strategies where strategies are constant and deterministic.

Proof. See Appendix B.

The equilibrium described in Theorem 3.1 is a "true" Markov perfect Nash equilibrium in the sense that, given the described (constant) strategy $\Phi_{1}$ of Player 1 , the described strategy $\Psi_{2}$ is the unique best response of Player 2 among the whole set of (constant and non-constant) admissible Markov strategies (and viceversa exchanging the role of Player 1 and Player 2).

This equilibrium is unique among equilibria where at least one the the players plays a constant deterministic strategy but it can fail to be unique in the set of all admissible couples strategies. In other words there could exist couples of Markov strategy (non-constant and deterministic for both players) which are equilibria. The problem of course is that agents could coordinate on equilibria which are

\footnotetext{
${ }^{8}$ Quantity $x_{i}$ is only a notation to ease the reading and has no intrinsic interpretation.
} 
different from the one described. A sort of "meta-analytical" justification can be used to defend the selection of the described equilibrium precisely because of its simplicity: an Occam's razor argument suggests indeed that the players could more easily coordinate on the simplest and more easily computable equilibrium.

Using the expressions of the land used by each player at the equilibrium we can easily determine the total amount of land converted for agricultural purposes and therefore, in a complementary way, the land available to preserve biodiversity. The result is contained in the corollary below.

Corollary 3.2. Suppose that hypotheses of Theorem 3.1 are satisfied. Then the total land area devoted to farming is

$$
\bar{f}:=\bar{f}_{1}+\bar{f}_{2}=\frac{x_{1}+x_{2}}{\phi_{1}+\phi_{2}-1} .
$$

To complete the analysis of the system at the equilibrium we can finally calculate the utility of each of the players:

Proposition 3.3. Suppose that the hypotheses of Theorem 3.1 are verified. Then, along the described equilibrium, the welfare of the two players is

$$
V_{i}\left(A_{1}, A_{2}\right)=\frac{\beta_{i}}{1-\theta_{i}} A_{i}^{1-\theta_{i}}
$$

with

$$
\beta_{i}=\left(\theta_{i} \frac{\sigma_{i}^{2}}{2} \bar{f}_{i}^{\phi_{i}}\right)^{-\frac{1-\theta_{i}}{1-\phi_{i}}}
$$

where the expression of $x_{i}$ and $\bar{f}_{i}$ are given respectively in (5) and in (9)-(10).

Since $V_{1}$ is only a function of $A_{1}$, we will simply write $V_{1}\left(A_{1}\right)$ instead of $V_{1}\left(A_{1}, A_{2}\right)$. Similarly for $V_{2}\left(A_{2}\right)$.

Proof. It is a corollary of the proof of Theorem 3.1. See Appendix B.

A first study of the results of the model is possible using the comparative analysis contained in the following proposition.

Proposition 3.4. Suppose that the hypotheses of Theorem 3.1 are satisfied. Then we have the following dependencies of $\bar{f}_{i}$ on the parameters characterizing Player $i$ :

$$
\frac{\partial \bar{f}_{i}}{\partial \rho_{i}}>0, \quad \frac{\partial \bar{f}_{i}}{\partial \sigma_{i}}<0, \quad \frac{\partial \bar{f}_{i}}{\partial \theta_{i}}<0,
$$


and on the parameters characterizing Player $j$ :

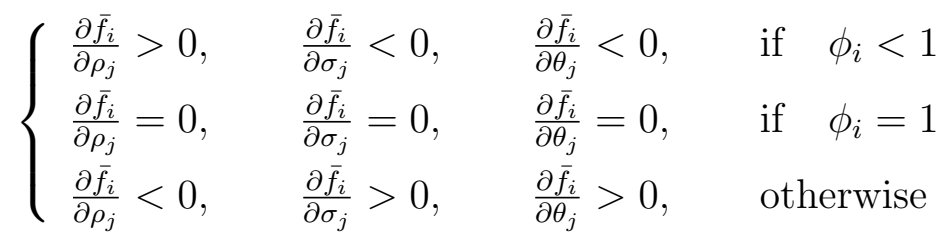

Proof. See Appendix B.

The trade-off agent $i$ faces when she chooses the amount of land $f_{i}$ she converts to agriculture is indeed between consuming more today (higher $f_{i}$ ) and having a smaller uncertainty tomorrow (higher $1-f_{i}$ ). Therefore the fact that $\frac{\partial \bar{f}_{i}}{\partial \rho_{i}}>$ 0 is rather intuitive: the higher is the subjective discount rate, the lower the importance of the future and then the higher the relative weight the player assigns to present consumption and the higher the $f_{i}$ she will choose. The effects of $\theta_{i}$ and $\sigma_{i}$ are pure risk-aversion effects: the higher $\sigma_{i}$ (respectively $\theta_{i}$ ) the higher the future volatility (respectively its perception) and then the higher the effort of the agent to reduce it.

To understand the effects of preference parameters of Player $j$ on the value of $\bar{f}_{i}$ it is instructive to have a look at the best response of Player $i$ to a generic choice $\bar{f}_{j}$ of Player $j$. It reads (see equations (46) and (48) in Appendix B):

$$
\bar{f}_{i}=\frac{x_{i}+\left(1-\phi_{i}\right) \bar{f}_{j}}{\phi_{i}}
$$

Then:

$$
\frac{d \bar{f}_{i}}{d \bar{f}_{j}} \begin{cases}>0 & \text { if } \quad \phi_{i}<1 \\ =0 & \text { if } \quad \phi_{i}=1 \\ <0 & \text { otherwise }\end{cases}
$$

If Player $i$ 's aversion to intertemporal fluctuations $\phi_{i}$ is smaller than 1 , her best response is to increase her share of land devoted to farming when Player $j$ increases her own. In this case, there is strategic complementarity. It is the reverse if $\phi_{i}$ is larger than 1: Player $i$, who is now strongly averse to intertemporal fluctuations, will decrease her share of land devoted to farming when Player $j$ increases her own. Now the decisions of the two players are strategic substitutes.

The total amount of land, that has to be divided between three uses: farming by Player 1 , farming by Player 2, and biodiversity conservation, is fixed. When Player $j$ chooses to convert more forest to farming, Player $i$, expecting more volatility of agricultural productivity in the future, may either increase $f_{i}$ to 
increase its average consumption at each date, or, on the contrary, decrease $f_{i}$ to counteract the volatility increase due to the behavior of Player $j$. The first effect is stronger than the second one when Player $i$ is not very averse to intertemporal fluctuations, and vice-versa. In case of strategic complementarity, the discount rate and the risk parameters of Player $j$ affect the behavior of Player $i$ in the same way as her own do. It is the reverse in case of strategic substitutability. When $\phi_{i}=1$ the two effects compensate exactly, and the decision of Player $i$ is independent of the choice made by Player $j$.

\section{The SYMmetric CASE AND THE COMPARISON WITH THE OPTIMAL SOLUTION}

To compare now the results with the optimal solution presented by AugeraudVéron et al. (2019) we consider the case where parameters $(\alpha, \sigma, \rho, \theta$ and $\phi)$ do not depend on $i$. We also suppose that the initial value of $A$ is the same for both farmers. More precisely we compare the decentralized solution at the symmetric equilibrium with the optimal solution chosen by a planner which gives in the

social welfare function the same weight to each farmer. We start by re-stating the result of Section 3 in this circumstances. In the next two subsections we will compare the results with the social planner benchmark in two perspectives: the biodiversity conservation and the welfare of the agents.

Define

$$
x=\frac{\rho-\alpha(1-\phi)}{\theta \frac{\sigma^{2}}{2}} .
$$

The results of Theorem 3.1 and Proposition 3.3 read as follows.

Corollary 4.1. Suppose that

$$
\rho>(1-\phi) \alpha
$$

(it implies in particular that $x$ is positive),

$$
\phi>1 / 2
$$

and that the following transversality condition is verified:

$$
\rho(1+2(\phi-\theta))>(1-\theta) \alpha
$$


Suppose that

$$
\bar{f}_{h}:=\frac{x}{2 \phi-1} \in\left[0, \frac{1}{2}\right]
$$

Then the couple

$$
\Psi_{2}\left(A_{1}, A_{2}\right) \equiv \bar{f}_{h}, \quad \Psi_{1}\left(A_{1}, A_{2}\right) \equiv \bar{f}_{h}
$$

is a Nash equilibrium of Markov strategies. Moreover it is the unique Nash equilibrium of Markov strategies where strategies are constant and deterministic. The total land used for farming is then

$$
\bar{f}:=2 \bar{f}_{h}=\frac{2 x}{2 \phi-1} \leq 1 .
$$

The corresponding welfare of each farmer is

$$
V_{h}(A)=\frac{\beta_{h}}{1-\theta} A^{1-\theta}
$$

with

$$
\beta_{h}=\left(\theta \frac{\sigma^{2}}{2} 2^{-\phi} \bar{f}^{\phi}\right)^{-\frac{1-\theta}{1-\phi}} .
$$

The expression of $\bar{f}$ given in (18) is particularly transparent. One can first easily verify that $\bar{f}$ is always a decreasing function of $\theta$. This is the same "risk hedging" reaction we have seen in Proposition 3.4 for the dependence of the values of $\bar{f}_{1}$ and $\bar{f}_{2}$ on $\theta_{1}$ and $\theta_{2}$. On the other hand we can observe that $\bar{f}$ is a decreasing function of $\phi$ if and only if $\alpha<2 \rho$. This condition relates to the comparison of the magnitudes of the growth and discount rates. When the trend of agricultural productivity is smaller than twice the discount rate, farmers' future prospects are not good. Then the more averse to fluctuations they are the more willing they are to insure against bad outcomes in the future by conserving more biodiversity. The opposite occurs when $\alpha>2 \rho$.

Notice that when $\alpha>2 \rho$, the two parameters characterizing preferences play in opposite directions. This is a strong argument in favor of disentangling the two parameters. See the discussion in Subsection 4.2.

\subsection{The effect of strategic competition on land use and biodiversity.} We recall that the part $f^{*}$ of land used for farming in the social planner model of Augeraud-Véron et al. (2019) is equal to

$$
f^{*}=\frac{x}{\phi} \text {. }
$$


The restrictions on the parameters which are needed to obtain this result are (14), a transversality condition which reads:

$$
\rho(1+(\phi-\theta))>(1-\theta) \alpha,
$$

and the condition $\frac{x}{\phi} \in[0,1]$. So, all in all, the conditions that allow to work in the intersection of the hypotheses needed for the current results and for the social planner case are the following: (14), (15), and

$$
\rho(1+\min [\phi-\theta, 2(\phi-\theta)])>(1-\theta) \alpha .
$$

When they are satisfied,

$$
\left\{\begin{array}{l}
f^{*}=\frac{x}{\phi} \quad \text { if } \quad x<\phi, \quad 1 \text { otherwise } \\
\bar{f}=\frac{x}{\phi-\frac{1}{2}} \quad \text { if } \quad x<\phi-\frac{1}{2}, \quad 1 \text { otherwise. }
\end{array}\right.
$$

The optimal share of land used for farming increases with the discount rate $\rho$, decreases when intrinsic volatility $\sigma$ increases, decreases when risk aversion $\theta$ increases, decreases when aversion to fluctuations $\phi$ increases if $\alpha<\rho$, and vice versa. Notice that, for $\rho<\alpha<2 \rho, f^{*}$ increases with $\phi$ whereas $\bar{f}$ decreases with $\phi$.

Define $\Lambda=\frac{\bar{f}}{f^{*}}$ the ratio of total land converted to farming at the Nash equilibrium and at the optimum. We have:

$$
\Lambda=\left\{\begin{array}{l}
\frac{\phi}{\phi-\frac{1}{2}}, \text { if } x<\phi-\frac{1}{2} \\
\frac{\phi}{x}, \text { if } \phi-\frac{1}{2} \leq x<\phi \\
1, \text { if } \phi \geq x .
\end{array}\right.
$$

Proposition 4.2. Suppose that (14), (15) and (23) are satisfied. Then $\Lambda \geq 1$ so that the land used for biodiversity conservation is weakly smaller in the strategic competition situation than that chosen by the social planner. $\Lambda$ is strictly greater than 1 as soon as the optimal land devoted to farming is strictly smaller than 1.

Proof. Direct inspection of formulas in (25).

Proposition 4.2 shows that a tragedy of the commons mechanism is at work in the model: the exploitation of the natural resource is larger in the strategic competition set-up than at the social optimum and then the land used for biodiversity conservation is smaller. This is what we expected since the two players do not completely internalize the volatility externality: the conversion decisions of 
each farmer affect the volatility of agricultural productivity and then the utility of both. In the following proposition we try to dig a little deeper into this result.

Proposition 4.3. Suppose that (14), (15) and (23) are satisfied and that $x \leq$ $\phi-\frac{1}{2}$, so that the solution is interior at the optimum and at the Nash equilibrium. Then $\Lambda$ does not depend on the risk aversion $\theta$ and is decreasing in the aversion to fluctuations $\phi$.

Proof. Direct inspection of the first formula in (25).

The previous proposition identifies the parameters that play a role in the gap between the optimal choice of land conversion and the outcome of a strategic competition for land appropriation between two identical farmers. The result is sharp: even if the risk aversion has a role in establishing the share of land devoted to production it has no impact on the gap between the optimal and the decentralized solutions. Conversely the elasticity of intertemporal substitution parameter does play a role: the smaller it is the higher is $\Lambda$, that is the further is the Nash solution from the optimal one.

\subsection{A technical excursus: comments on the role of the Epstein-Zin-} Weil utility. In this paper we have chosen to use the Epstein-Zin-Weil specification of preferences. Of course as a general statement there are several good reasons to disentangle the effect of risk aversion and intertemporal elasticity of substitution: they are related to different characteristics of the individuals, one concerning intra-temporal preferences, the other (as the name suggests) intertemporal behavior.

At the level of our model the relevance of this distinction is immediately clear once we look at the realistic possible values of the parameters (see for instance Barro, 2015). Plausible calibrations of the inverse of the intertemporal elasticity of substitution $\phi$ are smaller than 1 while the relative risk aversion parameter $\theta$ is typically largely higher than 1 (3 and more). This fact, besides pointing out once again the unlikelihood of the expected utility case $(\varphi=\theta=\phi)$, has qualitative implications in the model.

Disentangling the effect of risk aversion and intertemporal elasticity of substitution often gives the possibility of more deeply understanding some behaviors of the model. To clearly make the point consider for instance the value of the 
variable $x$ which appears several times in the paper. Its expression is

$$
x=\frac{\rho-\alpha(1-\phi)}{\theta \frac{\sigma^{2}}{2}}
$$

while its "expected utility counterpart" is given by

$$
x_{E U}=\frac{\rho-\alpha(1-\varphi)}{\varphi \frac{\sigma^{2}}{2}}
$$

where $\varphi$ is the unique parameter appearing in the expected utility case. One can readily see that the derivative $\frac{\partial x_{E U}}{\partial \varphi}$ does not have a univocal sign while the two derivatives $\frac{\partial x}{\partial \theta}$ and $\frac{\partial x}{\partial \phi}$ are respectively always negative and positive (under assumption (6)) so that introducing the two-parameters Epstein-Zin-Weil specification allows to resolve the ambiguity that we observe in the expected utility case. This explanatory effect of the Epstein-Zin-Weil specification on $x$ brings similar results to more interesting variables. If we look for instance at the expected utility counterpart of (18) (we could comment in a similar way (9) and (10)), it reads as

$$
\bar{f}_{E U}=\frac{2 x_{E U}}{2 \varphi-1}=\frac{2 \frac{\rho-\alpha(1-\varphi)}{\varphi \frac{\sigma^{2}}{2}}}{2 \varphi-1}
$$

The dependence of this expression on $\varphi$ relies on various relative magnitudes of the parameters and they are not easy to justify, while the signs of the two derivatives $\frac{\partial x}{\partial \theta}$ and $\frac{\partial x}{\partial \phi}$ is clear as we stressed in the discussion below Corollary 4.1: $\bar{f}$ is always a decreasing function of $\theta$ and it is an increasing function of $\phi$ if and only if $\alpha>2 \rho$. As discussed above these results have a neat economic interpretation.

Observe that in particular, as the two variables indicate different notions and characteristics, their effects on the agent's behavior can be very different. We have already mentioned above that, as far as $\alpha>2 \rho$ the role of $\theta$ and $\phi$ in establishing the size of the land devoted to farming (and then the size of the land devoted to biodiversity conservation) at the equilibrium $\bar{f}$ is opposite. This is also true for the size of the land devoted to farming at the social optimum $f^{*}$. 


\section{THE EFFECT OF STRATEGIC COMPETITION ON WELFARE AND POLICY}

\subsection{The per-capita welfare gain of moving from the Nash equilibrium} to the optimum. We restrict ourselves to the most interesting case where parameters are such that the solution at the Nash equilibrium is interior $(\bar{f}<1)$, which guarantees that the optimal solution is interior as well.

The welfare of each farmer at the Nash equilibrium is given in Proposition 3.3. At the optimum, the planner sets the level of $f$ at $f^{*}$ and then she gives half of total production to each farmer ${ }^{9}$. Since the production is linear in productivity, the welfare of each farmer is equal to the total welfare $V_{p}$ computed in AugeraudVéron et al. (2019), calculated for a productivity level equal to $A / 2$, where

$$
V_{p}(A)=\frac{1}{1-\theta} \beta_{p} A^{1-\theta}
$$

with

$$
\beta_{p}=\left(\theta \frac{\sigma^{2}}{2}\left(f^{*}\right)^{\phi}\right)^{-\frac{1-\theta}{1-\phi}} .
$$

We define the welfare gain of moving from the Nash equilibrium to the optimum as the permanent percentage increase in consumption that has to be given to each farmer in order to increase her welfare up to the optimal level. This welfare gain is denoted $\omega$ and defined by:

$$
V_{h}((1+\omega) A)=V_{p}\left(\frac{A}{2}\right) .
$$

Using equations (26), (27), (19) and (20) we obtain:

$$
\omega=\left[\frac{1}{2}\left(\frac{\phi}{\phi-\frac{1}{2}}\right)^{\phi}\right]^{\frac{1}{1-\phi}}-1
$$

and can prove the following proposition:

Proposition 5.1. Suppose that hypotheses of Corollary 4.1 are verified. $\omega$ is always positive, does not depend on risk aversion and is a decreasing function of aversion to fluctuations.

\footnotetext{
${ }^{9}$ This result relies on the fact that all farmers have the same preferences and the same initial productivity. We also suppose that the planner attaches the same weight to each farmer in the social welfare function.
} 
Proof. See Appendix B.

\subsection{Decomposition of the total value of biodiversity and policy im-} plications of the model. In reference to Lucas' welfare cost of fluctuations (Lucas, 1987), the total value of biodiversity can be defined as the welfare gain from conserving biodiversity at its optimal value compared to no conservation at all. More precisely, is the percentage increase in consumption society is willing to accept at all dates to give up the optimal level of biodiversity in favor of no biodiversity at all (see Augeraud-Véron et al., 2019).

The case where the whole forest is converted to farming and no biodiversity is conserved can be interpreted as the consequence of a forest in open access, where property rights are absent or poorly defined or enforced. Then each farmer appropriates $1 / 2$ of total land and all land is converted to farming. Following Augeraud-Véron et al. (2019), the utility in this case is ${ }^{10}$ :

$$
V_{o a}(A)=\frac{1}{1-\theta} \beta_{o a} A^{1-\theta}
$$

with, when the restriction on parameters

$$
\rho>(1-\phi)\left(\alpha-\theta \frac{\sigma^{2}}{2}\right)
$$

is satisfied,

$$
\beta_{o a}=\left[\rho-(1-\phi)\left(\alpha-\theta \frac{\sigma^{2}}{2}\right)\right]^{-\frac{1-\theta}{1-\phi}} .
$$

The per capita welfare gain from biodiversity conservation is then $\lambda$ defined by:

$$
V_{o a}\left((1+\lambda) \frac{A}{2}\right)=V_{p}\left(\frac{A}{2}\right) .
$$

Using equations (26), (27), (30) and (32) we obtain:

$$
\lambda=\left(\frac{\phi f^{*}+(1-\phi)}{f^{* \phi}}\right)^{\frac{1}{1-\phi}}-1 .
$$

\footnotetext{
${ }^{10}$ Indeed the utility is computed in Augeraud-Véron et al. (2019) using a sort of "trick" that can be used only because we consider a constant control. They observe that the welfare in the situation where we impose that all the land is used for farming is indeed the value function of a different (auxiliary) optimization problem where the agents can only choose to take $f_{1}=f_{2}=1 / 2$ so we can compute the utility in the situation where we impose $f=1 / 2$ just computing the value function of the problem where the agents, instead of maximizing on the set $[0,1]$ maximize on the set (singleton) $\{1 / 2\}$ and so they are obliged to choose $f_{1}=f_{2}=1 / 2$.
} 
$\lambda$ decreases when the discount rate $\rho$ increases, increases (resp. decreases) when the trend of agricultural productivity increases if $\phi<1$ (resp. $>1$ ), increases with the intrinsic volatility $\sigma$, increases with the risk aversion $\theta$ and is an ambiguous function of the aversion to fluctuations $\phi$. Augeraud-Véron et al. (2019) show that when $\alpha<\rho, \lambda$ unambiguously increases with $\phi$. In this case, a higher aversion to fluctuations translates into more biodiversity conservation and a higher value of biodiversity. In the opposite case where $\alpha>\rho$, the effect of $\phi$ on $\lambda$ is ambiguous. Then, increasing aversion to fluctuations decreases the share of land devoted to biodiversity conservation and may at the same time increase the total value of biodiversity.

The total insurance value of biodiversity $\lambda$ can be decomposed in two parts: the welfare gain of moving from the open access equilibrium to the Nash equilibrium, denoted $\bar{\lambda}$, and the welfare gain of moving from the Nash equilibrium to the optimum, $\omega$. Assessing the relative magnitudes of these two components is important for policy. Indeed, if the insurance value of biodiversity is mostly due to the departure from the open access situation, then the appropriate policy consists in dividing total land equally among farmers and giving them secure property rights on their plot; if on the contrary it is mostly due to the lack of internalization of the volatility externality, then the appropriate policy consists in pricing the volatility externality, for instance through a tax on land conversion.

Similarly to the definition of $\lambda, \bar{\lambda}$ is defined by:

$$
V_{\text {oa }}\left((1+\bar{\lambda}) \frac{A}{2}\right)=V_{h}\left(\frac{A}{2}\right) \text {. }
$$

It is easy to see that the decomposition reads:

$$
1+\lambda=(1+\omega)(1+\bar{\lambda})
$$

5.3. Illustrative simulations. To get more insights on the relative magnitude of the three welfare gains identified above we perform illustrative simulations using the following values of the parameters: $\theta=3, \rho=0.04$ and $\sigma=0.25$, in three configurations: $\alpha=0.035<\rho, \rho<\alpha=0.05<2 \rho, 2 \rho<\alpha=0.085$. The value chosen for $\theta$ is empirically relevant (see for instance Barro, 2015). The value of $\rho$ is in the standard range considered in dynamic models and it is for instance consistent with the data from Lopez (2008). The range of values of $\alpha$ is consistent with the growth rates observed in developing countries (see e.g. World Bank Group, 2018). We have chosen on purpose a very high volatility of 
agricultural productivity, implying a variance $\sigma^{2}$ of $6.25 \%$, in the case where all land is converted to farming, to reflect firstly the fact that agricultural output is more volatile than global output, and second that without the dampening effect of biodiversity this volatility will become very high. Finally we suppose that aversion to fluctuation $\phi$ is smaller than risk aversion $\theta$. All in all, our calibration is related to the case of biodiversity-rich developing countries where agricultural productivity is very volatile, deforestation and land conversion are an issue, and farmers have a preference for the early resolution of uncertainty (Gollier, 2001), in the sense that they are more risk averse than they are concerned about smoothing consumption. ${ }^{11}$

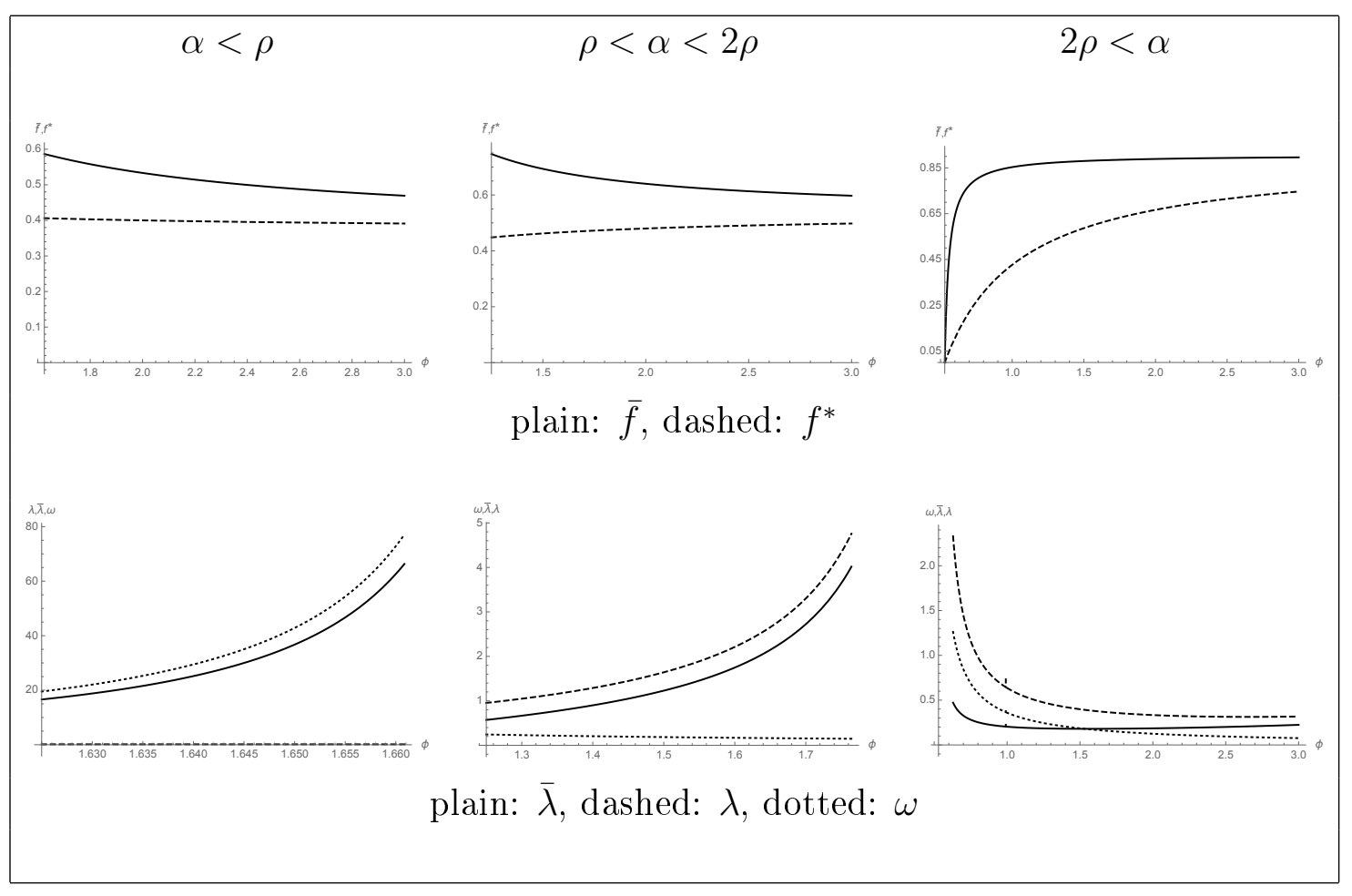

FIGURE 1. Land conversion (upper panel) and welfare gains (lower panel) as functions of aversion to fluctuations

Figure 1 shows the amount of land converted to farming at the Nash equilibrium and at the optimum (upper panel) and the three welfare gain measures

\footnotetext{
${ }^{11}$ See for instance Lybbert and McPeak (2012) for an empirical highlighting of the preference for an early resolution of uncertainty in the case of an agricultural economy.
} 
(lower panel) as functions of aversion to fluctuations $\phi$, in the three configurations identified as relevant for the relative magnitudes of $\alpha$ and $\rho$. The range of $\phi$ is such that the restrictions necessary to obtain interior solutions and the transversality conditions are satisfied, and there is preference for early resolution of uncertainty. In the lower panel the restriction on parameters (31) is added to ensure the existence of the welfare gains.

In the first and second cases depicted on Figure 1, the trend of agricultural productivity is smaller than twice the discount rate. Then the welfare gain of conserving the optimal level of biodiversity is increasing in the aversion to fluctuations, whereas the welfare gain from moving from the Nash equilibrium to the optimum is decreasing in the aversion to fluctuations. Then as $\phi$ increases the welfare gain of conserving the optimal level of biodiversity becomes mostly explained by the welfare gain of moving from the open access situation to the Nash equilibrium. These results suggest that the most relevant policy option in poorly productive agricultural economies is to put in place land property rights to move away from open access.

In the third case, where the agricultural productivity trend is very high compared to the discount rate, the effects may be very different since the welfare gain of conserving the optimal level of biodiversity is decreasing in the aversion to fluctuations. We exhibit in the simulation a case where this welfare gain is mostly explained by the welfare gain of moving from the open access situation to the Nash equilibrium when $\phi$ is small, then more and more explained by the welfare gain of moving from the open access situation to the Nash equilibrium as $\phi$ increases.It suggests that in highly productive economies averse to fluctuations the best policy option may be to tax land conversion to internalize the volatility externality.

\section{EXtension to THE $n$-PLAYER CASE}

The results obtained for the two-player case can be extended to the $n$-player case. In this section we briefly sketch the results in the general case.

As proved in Appendix $\mathrm{C}$ the best response function of Player $i$ to the decisions of the other players is:

$$
\bar{f}_{i}=\frac{1}{\phi_{i}}\left(x_{i}+\left(1-\phi_{i}\right) \sum_{j \neq i} \bar{f}_{j}\right) .
$$


As in the two-player case, there is strategic complementarity if $\phi_{i}<1$, strategic substitutability if $\phi_{i}>1$, and the decision of Player $i$ is independent of the choices of the other players when $\phi_{i}=1$. Moreover, the interior Nash equilibrium is characterized by the following set of strategies:

$$
\bar{f}_{i}=\min \left(\frac{x_{i}\left(\sum_{\substack{j=1 \\ j \neq i}}^{n} \phi_{j}-(n-2)\right)+\left(1-\phi_{i}\right) \sum_{\substack{j=1 \\ j \neq i}}^{n} x_{j}}{\sum_{j=1}^{n} \phi_{j}-(n-1)}, 1-\sum_{\substack{j=1 \\ j \neq i}}^{n} f_{j}\right) .
$$

When preferences parameters are the same for all players and $\phi>1-\frac{1}{n}$, according to (38), the interior optimal quantity of land devoted to farming for each farmer in the $n$-player game is given by

$$
\bar{f}_{h}=\frac{x}{n \phi+1-n} \in\left[0, \frac{1}{n}\right]
$$

and then the total land devoted to farming is

$$
\bar{f}=\frac{x}{\phi-\frac{n-1}{n}} \leq 1
$$

If can be noticed that

$$
\frac{d \bar{f}_{h}}{d n}\left\{\begin{aligned}
>0 & \text { if } \phi<1 \\
=0 & \text { if } \phi=1 \\
<0 & \text { otherwise }
\end{aligned} \text { and } \frac{d \bar{f}}{d n}>0 .\right.
$$

Not surprisingly, as the number of farmers increases, the total share of land devoted to biodiversity conservation decreases. The more farmers there are the bigger the volatility externality. The open access situation corresponds to the case of free entry, where new farmers appropriate land until all land is converted to farming.

More interestingly, how individual choices depend on the number of farmers is radically different whether the aversion to intertemporal fluctuations is less or more than 1. We have seen in Section 3 that farmers' decisions are strategic complements when $\phi<1$; then, when the number of farmers increases every individual share of land devoted to farming increases as well. In this sense, a small aversion to intertemporal fluctuations is detrimental to biodiversity conservation. 
Conversely, if farmers have a large aversion to intertemporal fluctuation $(\phi>$ 1 ), farmers' decisions are strategic substitutes and when the number of farmers increases each one reduces its own farming.

In the $n$-player situation, the relationship $1+\lambda=(1+\omega)(1+\bar{\lambda})$ still holds, with $\lambda$ unchanged and (see Appendix C)

$$
\omega=\left(\frac{1}{n}\left(\frac{\phi}{\phi+\frac{1}{n}-1}\right)^{\phi}\right)^{\frac{1}{1-\phi}}-1
$$

We can see that

$$
\frac{\partial \omega}{\partial n}=\frac{\left(1-\frac{1}{n}\right)\left(\frac{\left(\frac{\phi}{\phi+\frac{1}{n}-1}\right)^{\phi}}{n}\right)^{\frac{1}{1-\phi}}}{1+n(\phi-1)}
$$

thus as $\phi>1-\frac{1}{n}, \omega$ is an increasing function of $n$. The more farmers there are the bigger the gain of putting in place land property rights.

\section{CONCLUSiON}

Biodiversity is a multiform concept, as are the ways to calculate its economic value. Biodiversity is in particular a flow of services that allows to reduce the variability of ecological and economic conditions and can therefore be thought of, among other things, as a natural form of insurance. What is the loss of biodiversity insurance value that results from the decentralized decision of individuals and volatility externalities? Under which conditions is this loss most pronounced? What policies are best suited to counter this loss?

In this article we propose a theoretical framework to approach these questions. We consider an agricultural economy with free access and use of a natural forest. A trade-off arises between the forest conversion to agricultural activity and the loss of biodiversity and consequently of its role of natural insurance this conversion entails.

We study the solution of the model in a context of strategic competition among farmers, quantifying the over-exploitation of the forest and the welfare loss with respect to the social optimum. Agents' utility is given in terms of a Kreps Porteus stochastic differential utility capable of disentangling risk aversion and aversion to fluctuations. 
For empirically plausible values of the parameters, the model suggests that enforcing property rights is more relevant in case of stagnant technological progress in agricultural activities while policies consisting in pricing the volatility externality (for instance through a tax on land conversion) may be more suited for rapidly developing economies averse to fluctuations.

The structure of the proposed benchmark model is kept simple to allow the model to be solved explicitly, but a number of possible extensions would be of interest. We mention here some of them.

A a first extension of the model could include production storage technologies. In this way the consumption at any given time would not need to be equal to production and the smoothing of the consumption trajectory could go through a new channel compared to the model presented in this paper.

A second possible generalization could take into account catastrophic events that may have an impact on production/productivity and whose frequency or magnitude could be endogenously influenced by conservation choices as suggested by a great deal of evidence (for example, see Isbell et al., 2015).

A third way to extend the current results could consist in considering the different impacts of different agricultural models on biodiversity following the well-developed discussion about land sparing vs land sharing, since a part of the biodiversity could be preserved also in agricultural environments depending on the farming practices.

\section{REFERENCES}

Arrhenius, O. (1921). Species and Area. Journal of Ecology 9:95-99.

Augeraud-Véron, E., Fabbri, G., and Schubert, K. (2019). The value of biodiversity as an insurance device. American Journal of Agricultural Economics, 101(4), 1068-1081.

Baland, J.-M. and Francois,P. (2005). Commons as insurance and the welfare impact of privatization. Journal of Public Economics, 89 (2): 211-231. 
Banerjee, A. and Duflo, E. (2010). Giving credit where it is due. Journal of Economic Perspectives, 24(3), 61-80.

Barro, R. J. (2015). Environmental protection, rare disasters and discount rates. Economica, 82(325), 1-23.

Baumgärtner, S. (2007). The insurance value of biodiversity in the provision of ecosystem services. Natural Resource Modeling 20(1), 87-127.

Baumgärtner, S., and Quaas, M. F. (2010). Managing increasing environmental risks through agrobiodiversity and agrienvironmental policies. Agricultural Economics, 41(5), 483-496.

Baumgärtner, S. and Strunz, S. (2014). The economic insurance value of ecosystem resilience. Ecological Economics 101, 21-32.

Brook, B. W., Sodhi, N. S. and Ng, P. K. L. (2003), Catastrophic extinctions follow deforestation in Singapore. Nature 424, 420-426.

Delacote, P. (2009). Commons as insurance: Safety nets or poverty traps? Environment and Development Economics, 14(3), 305-322.

Di Falco, S., Perrings, C. (2005). Crop biodiversity, risk management and the implications of agricultural assistance. Ecological economics, 55(4), 459-466.

Duffie, D. and Epstein, L. G. (1992a). Stochastic differential utility. Econometrica, 60(2), 353-94.

Duffie, D. and Epstein, L. G. (1992b). Asset Pricing with Stochastic Differential Utility. The Review of Financial Studies, 5(3), 411-436.

Duffie, D. and Lions, P. L. (1992). PDE solutions of stochastic differential utility. Journal of Mathematical Economics, 21(6), 577-606.

Gleason, H. A. (1922), On the relation between species and area. Ecology 3, $158-162$.

Epaulard, A. and Pommeret, A. (2003). Optimally eating a stochastic cake: a recursive utility approach. Resource and Energy Economics 25(2), 129-139. 
Epstein, L. and Zin, S. (1991). Substitution, risk aversion, and the temporal behavior of consumption and asset returns: an empirical analysis. Journal of Political Economy 99(2), 261-286.

FAO (2018). The future of food and agriculture: alternative pathways to 2050 . Food and Agriculture Organization of the United Nations, Rome.

Fischer, J., Abson, D. J., Butsic, V., Chappell, M. J., Ekroos, J., Hanspach, J., Kuemmerle, T., Smith, H.G., and von Wehrden, H. 2014. Land sparing versus land sharing: moving forward. Conservation Letters 7(3): 149-157.

Gollier, C., 2001. The Economics of Risk and Time. MIT Press, Cambridge, Mass.

Green, R. E., Cornell, S.J., Scharlemann, J.P.W. and Balmford, A. (2005). Farming and the fate of wild nature, Science 307, 550-555.

Howitt, R. E., Msangi, S., Reynaud, A. and Knapp, K. C. (2005). Estimating intertemporal preferences for natural resource allocation. American Journal of Agricultural Economics 87(4), 969-983.

Isbell, F., Craven, D., Connolly, J., Loreau, M., Schmid, B., Beierkuhnlein, C., Bezemer, T.M., Bonin, C., Bruelheide, H., De Luca, E. and Ebeling, A. (2015). Biodiversity increases the resistance of ecosystem productivity to climate extremes. Nature, 526(7574), 574-577.

IPBES (2019). Global Assessment Report on Biodiversity and Ecosystem Services.

Knapp, K. and Olson, L. (1996). Dynamic resource management: Intertemporal substitution and risk aversion, American Journal of Agricultural Economics 78(4), 1004-1014.

Kraft, H., and Seifried, F. T. (2014). Stochastic differential utility as the continuous-time limit of recursive utility. Journal of Economic Theory 151: $528-550$.

Kremen, C. (2005). Managing ecosystem services: what do we need to know about their ecology? Ecology Letters, 8(5), 468-479. 
Lafuite, A.-S. and Loreau, M. (2017). Time-delayed biodiversity feedbacks and the sustainability of social-ecological systems. Ecological Modelling 351, 96-108.

Lasserre, P and Kassar, I. (2004). Species preservation and biodiversity value: A real option approach. Journal of Environmental Economics and Management $48(2), 857-879$.

Lazrak, A., and Quenez, M. C. (2003). A generalized stochastic differential utility. Mathematics of operations research 28(1): 154-180.

Lucas, R. (1987). Models of business cycles, Blackwell, Oxford.

Lopez, H. (2008). The social discount rate: estimates for nine Latin American countries. The World Bank Policy Research Working Paper Series 4639.

Loreau, M. and Mazancourt, C. (2013). Biodiversity and ecosystem stability: A synthesis of underlying mechanisms. Ecology Letters, 16(s1), 106-115.

Lybbert, T.J. and McPeak, J. (2012). Risk and intertemporal substitution: Livestock portfolios and off-take among Kenyan pastoralists. Journal of Development Economics 97(2), 415-426.

Maille, P. and Mendelsohn, R. (1993). Valuing ecotourism in Madagascar. Journal of Environmental Management, 38(3), 213-218.

Noack, F., Riekhof, M.-C. and Di Falco, S. (2019). Droughts, Biodiversity, and Rural Incomes in the Tropics. Journal of the Association of Environmental and Resource Economists, 6(4), 823-852.

Protter, P. (2005). Stochastic Integration and Differential Equations, Second Edition, Stochastic Modelling and Applied Probability Vol. 21. Springer:Berlin.

Quaas, M.F., Baumgärtner, S., Becker, C., Frank, K. and Mller, B. (2007). Uncertainty and sustainability in the management of rangelands. Ecological Economics 62(2), 251-266.

Quaas, M. F., and Baumgärtner, S. (2008). Natural vs. financial insurance in the management of public-good ecosystems. Ecological Economics 65(2), 397-406.

Quaas, M. F., Baumgärtner, S. and De Lara, M. (2019). Insurance value of natural capital. Ecological Economics 165. 
Renwick, A., and Schellhorn, N. (2016). A perspective on land sparing versus land sharing. in Learning from agri-environment schemes in Australia, 117.

Simpson, R.D., Sedjo, R.A. and Reid, J.W., 1996. Valuing biodiversity for use in pharmaceutical research. Journal of Political Economy, 104(1), 163-185.

Smith, W. T. (1996). Feasibility and transversality conditions for models of portfolio choice with non-expected utility in continuous time. Economics Letters $53,123-131$.

Storch, D., Keil, P., and Jetz, W. (2012). Universal species?area and endemicsarea relationships at continental scales. Nature, 488(7409), 78-81.

World Bank Group (2018). World Development Indicators 2018. World Bank Publications.

\section{Appendix A. The utility specificAtion And the Definition of EQUILIBRIUM}

We spend some words to recall how this utility is defined. We start by defining the utility for the finite horizon problem with horizon $T>0$. Chosen a couple of strategies $\left(\Psi_{1}, \Psi_{2}\right) \in \mathcal{C}$ we have, through (3), the dynamics of $A_{1}$ and $A_{2}$ and then, thanks to (2) the processes $Y_{i}$, and (with (4)) the consumptions paths. The Epstein-Zin-Weil utility (for player 1, the situation for player 2 is completely analogous) is defined (see Duffie and Epstein, 1992a, 1992b) as the solution at time $t=0$ of the following integral equation (it is a backward SDE with final condition equal to 0 ):

$$
U_{1}^{t, T}\left(\Psi_{1}, \Psi_{2}\right)=\mathbb{E}\left[\int_{t}^{T} F_{1}\left(C_{1}(s), U_{1}^{s, T}\left(\Psi_{1}, \Psi_{2}\right)\right) d s \mid \mathcal{F}_{t}\right]
$$


where the aggregator $F$ can be chosen ${ }^{12}$ in the following form (Epstein and Zin, 1991, Svensson, 1989 and and Duffie and Epstein, 1992a) :

$$
F_{1}(C, V)=\frac{\rho}{1-\phi_{i}}\left(1-\theta_{i}\right) V\left[\left(\frac{C}{\rho\left(\left(1-\theta_{i}\right) V\right)^{\frac{1}{1-\theta_{i}}}}\right)^{1-\phi_{i}}-1\right] .
$$

One of the most characteristic properties of Epstein-Zin-Weil utilities, apart from the partular case where $\phi_{i}=\theta_{i}$, is that they are not separable in the sense that they cannot be written as a double integral (one with respect to time and one, hope, with respect to the probability measure). For this reason, in the general case utility can only be expressed by an expression of the form (39).

In the infinite horizon case the utility is defined as

$$
U_{1}\left(\Psi_{1}, \Psi_{2}\right)=\lim _{T \rightarrow \infty} U_{1}^{0, T}\left(\Psi_{1}, \Psi_{2}\right)
$$

Proving that this utility is well defined is not in general an easy problem (one has to be sure that the backward equation has a solution and that the limit exists). Results for existence are given for instance by Duffie and Epstein (1992a) in the finite horizon case, and by Duffie and Lions (1992) in the infinite horizon Kreps Porteus case (i.e. the case we are interested in).

Given a strategy $\Psi_{2}$ of farmer 2 we say that $\Psi_{1} \in \mathcal{C}_{1}\left(\Psi_{2}\right)$ is a best response to $\Psi_{2}$ if

$$
\Psi_{1} \in \arg \max _{\Phi \in \mathcal{C}_{1}\left(\Psi_{2}\right)} U_{1}\left(\Phi, \Psi_{2}\right) .
$$

Similarly, given a strategy $\Psi_{1}$ of farmer $1, \Psi_{2} \in \mathcal{C}_{2}\left(\Psi_{1}\right)$ is a best response to $\Psi_{1}$ if

$$
\Psi_{2} \in \arg \max _{\Phi \in \mathcal{C}_{2}\left(\Psi_{2}\right)} U_{1}\left(\Psi_{1}, \Phi\right) .
$$

We say that the couple $\left(\Psi_{1}, \Psi_{2}\right)$ is a Nash equilibrium of Markov strategies if both (41) and (42) are verified.

\section{Appendix B. Proofs in the 2-PLAYER CASE}

Proof of Theorem 3.1. Suppose first that Player 2 plays a constant strategy $\Psi_{2}\left(A_{1}, A_{2}\right) \equiv f_{2}$ for some $f_{2} \in[0,1]$. Then the optimal response of Player 1 can be found as the solution (in feedback form) of an optimal control whose Bellman equation may be written as:

\footnotetext{
${ }^{12}$ Several ordinally equivalent choices of the aggregator are possible, the one described in (40) has the advantage of eliminating the variance term that in general appears in (39), it is indeed the unique with this property, see Duffie and Epstein (1992b) and Duffie and Lions (1992).
} 


$$
\begin{aligned}
\rho_{i} \frac{1-\theta_{i}}{1-\phi_{i}} V_{i}\left(A_{1}, A_{2}\right) & =\max _{f_{i} \in\left[0,1-f_{j}\right]}\left[\frac{\left(f_{i} A_{i}\right)^{1-\phi_{i}}}{1-\phi_{i}} \frac{1}{\left(\left(1-\theta_{i}\right) V_{i}\left(A_{1}, A_{2}\right)\right)^{\frac{1-\phi_{i}}{1-\theta_{i}}-1}}+\right. \\
& \left.\frac{\partial V_{i}}{\partial A_{1}} A_{1} \alpha_{1}+\frac{\partial V_{i}}{\partial A_{2}} A_{2} \alpha_{2}+\frac{1}{2}\left(f_{1}+f_{2}\right)\left\langle\left(\begin{array}{c}
\sigma_{1} \\
\sigma_{2}
\end{array}\right), H V_{i}\left(\begin{array}{c}
\sigma_{1} \\
\sigma_{2}
\end{array}\right)\right\rangle\right]
\end{aligned}
$$

We guess and check the following solution: $V_{1}\left(A_{1}, A_{2}\right)=\beta_{1} \frac{A_{1}^{1-\theta_{1}}}{1-\theta_{1}}$ for some positive constant $\beta_{1}$. Then

$$
\rho_{1} \frac{1}{1-\phi_{1}} \beta_{1} A_{1}^{1-\theta_{1}}=\max _{f_{1}}\left[\frac{\left(f_{1} A_{1}\right)^{1-\phi_{1}}}{1-\phi_{1}} \frac{1}{\left(\beta_{1} A_{1}^{1-\theta_{1}}\right)^{\frac{1-\phi_{1}}{1-\theta_{1}}-1}}+\beta_{1} A_{1}^{1-\theta_{1}}\left[\alpha_{1}-\theta_{1} \frac{\sigma_{1}^{2}}{2}\left(f_{1}+f_{2}\right)\right]\right]
$$

i.e.

$$
\frac{\rho_{1}}{1-\phi_{1}}=\max _{f_{1}}\left[\frac{f_{1}^{1-\phi_{1}}}{\left(1-\phi_{1}\right) \beta_{1}^{\frac{1-\phi_{1}}{1-\theta_{1}}}}+\left[\alpha_{1}-\theta_{1} \frac{\sigma_{1}^{2}}{2}\left(f_{1}+f_{2}\right)\right]\right]
$$

i.e.

$$
\frac{\rho_{1}}{1-\phi_{1}}-\alpha_{1}=\max _{f_{1}}\left[\frac{f_{1}^{1-\phi_{1}}}{\left(1-\phi_{1}\right) \beta_{1}^{\frac{1-\phi_{1}}{1-\theta_{1}}}}-\theta_{1} \frac{\sigma_{1}^{2}}{2}\left(f_{1}+f_{2}\right)\right]
$$

The maximizer $f_{1}$ on $(0,+\infty)$ (we will check later that point of maximum will be in $\left.\left(0,1-f_{2}\right]\right)$ is given by the solution of

$$
\frac{f_{1}^{-\phi_{1}}}{\beta_{1}^{\frac{1-\phi_{1}}{1-\theta_{1}}}}=\theta_{1} \frac{\sigma_{1}^{2}}{2}
$$

If we replace $\beta_{1}^{\frac{1-\phi_{1}}{1-\theta_{1}}}$ taken from (44) into (43) we get:

$$
\rho_{1}-\alpha_{1}\left(1-\phi_{1}\right)=\theta_{1} \frac{\sigma_{1}^{2}}{2}\left[f_{1} \phi_{1}-\left(1-\phi_{1}\right) f_{2}\right]
$$

i.e.

$$
f_{1}=\frac{1}{\phi_{1}}\left(x_{1}+\left(1-\phi_{1}\right) f_{2}\right)
$$

where $x_{i}$ is defined as in (5). If this expression belongs in $\left[0,1-f_{2}\right]$, using classical results for optimization of problems with stochastic differential utilities and infinite horizon (see for instance Appendix C of Duffie et Epsten, 1992a), the feedback optimal 
control of Player 1 when she knows that Player 2 plays $\Psi_{2}\left(A_{1}, A_{2}\right) \equiv f_{2}$ (i.e. her optimal response) is $\Psi_{1}\left(A_{1}, A_{2}\right) \equiv f_{1}$ if a transversality condition in the form (see Smith, 1996):

$$
\lim _{t \rightarrow \infty} \mathbb{E}_{0}\left[e^{-\rho_{1} t} V_{1}\left(A_{1}(t)\right)\right]=0
$$

is verified. In this expression, and in the following, to lighten the notation, since $V_{1}$ is only a function of $A_{1}$, we simply write $V_{1}\left(A_{1}\right)$.

We will verify it at the equilibrium.

A similar argument can be used for Farmer 2 responding to a constant strategy of Farmer 1. The equation which corresponds to (46) is then

$$
f_{2}=\frac{1}{\phi_{2}}\left(x_{2}+\left(1-\phi_{2}\right) f_{1}\right)
$$

The solution of the system (46)-(48) gives (9)-(10). Thanks to hypotheses of the Theorem the couple $\Psi_{2}\left(A_{1}, A_{2}\right) \equiv \bar{f}_{2}, \Psi_{1}\left(A_{1}, A_{2}\right) \equiv \bar{f}_{1}$ is an admissible couple. When the players use this couple the total area devoted to farming is, as described in (11), $\bar{f}:=\bar{f}_{1}+\bar{f}_{2}=\frac{x_{1}+x_{2}}{\phi_{1}+\phi_{2}-1}$. To conclude the proof we only need to see that, along the equilibrium path the condition (47) and its counterpart for Player 2 are verified. We can see that

$\mathbb{E}_{0}\left[e^{-\rho_{i} t} V_{i}(A(t))\right]=\frac{\beta_{i}}{1-\theta_{i}} \lim _{t \rightarrow \infty} e^{-\rho_{i} t} \mathbb{E}_{0}\left[A_{i}(t)^{1-\theta_{i}}\right]=\frac{\beta_{i}}{1-\theta_{i}} A_{0} \lim _{t \rightarrow \infty} e^{-\rho_{i} t} e^{\left(1-\theta_{i}\right)\left(\alpha_{i}-\theta_{i} \frac{\sigma_{i}^{2}}{2} \bar{f}\right) t}$,

and one can easily see that both (for $i=1,2$ ) these expressions goes to 0 under the conditions (8).

Finally we can observe that, since the solution of the two equations (46) and (48) is unique, so it is the equilibrium of constant strategies.

Remark B.1. Observe that, s long as the drift and the diffusion terms in equation (3) remains linear in $A$ there are several degrees of freedom with respect to our specification in order to obtain existence of a Markov perfect equilibrium of constant strategy.

More precisely, if we consider the generic specification

$$
\mathrm{d} A_{i}(t)=\alpha_{i}\left(f_{1}, f_{2}\right) A_{i}(t) \mathrm{d} t+\sigma_{i}\left(f_{1}, f_{2}\right) A_{i}(t) \mathrm{d} W(t)
$$

there exists a constant and deterministic equilibrium $\left(\Psi_{1}, \Psi_{2}\right)=\left(\bar{f}_{1}, \bar{f}_{2}\right)$ if the following conditions are verified for some $\beta_{1}, \beta_{2}>0$ :

$$
0<\bar{f}_{1} \in \arg \max _{f_{1}}\left[\frac{f_{1}^{1-\phi_{1}}}{\left(1-\phi_{1}\right) \beta_{1}^{\frac{1-\phi_{1}}{1-\theta_{1}}}}+\left[\alpha_{1}\left(f_{1}, \bar{f}_{2}\right)-\theta_{1} \frac{\sigma_{1}\left(f_{1}, \bar{f}_{2}\right)^{2}}{2}\right]\right]
$$




$$
\begin{gathered}
0<\bar{f}_{2} \in \arg \max _{f_{2}}\left[\frac{f_{2}^{1-\phi_{2}}}{\left(1-\phi_{2}\right) \beta_{2}^{\frac{1-\phi_{2}}{1-\theta_{2}}}}+\left[\alpha_{2}\left(\bar{f}_{1}, f_{2}\right)-\theta_{2} \frac{\sigma_{2}\left(\bar{f}_{1}, f_{2}\right)^{2}}{2}\right]\right] \\
\bar{f}_{1}+\bar{f}_{2}<1 .
\end{gathered}
$$

This system has a solution for several specification of $\alpha_{i}$ and $\theta_{i}$. The problem (and the reason why we concentrated on the version that we study in the paper) is that very rarely the solution of the system can be written explicitly and then studied in detail.

Proof of Proposition 3.4. By direct computation we have

$$
\begin{aligned}
\frac{\partial \bar{f}_{1}}{\partial \rho_{1}} & =\frac{\partial x_{1}}{\partial \rho_{1}} \frac{\phi_{2}}{\phi_{1}+\phi_{2}-1}>0 \\
\frac{\partial \bar{f}_{1}}{\partial \theta_{1}} & =\frac{\partial x_{1}}{\partial \theta_{1}} \frac{\phi_{2}}{\phi_{1}+\phi_{2}-1}<0 \\
\frac{\partial \bar{f}_{1}}{\partial \sigma_{1}} & =\frac{\partial x_{1}}{\partial \sigma_{1}} \frac{\phi_{2}}{\phi_{1}+\phi_{2}-1}<0
\end{aligned}
$$

and similarly when we compute $\frac{\partial \bar{f}_{2}}{\partial \rho_{2}}, \frac{\partial \bar{f}_{2}}{\partial \theta_{2}}$ and $\frac{\partial \ln \bar{f}_{2}}{\partial \sigma_{2}}$. Conversely, when we compute the derivatives of $\bar{f}_{1}$ w.r.t. to parameters of player 2 we get

$$
\begin{aligned}
\frac{\partial \bar{f}_{1}}{\partial \rho_{2}} & =\frac{\partial x_{2}}{\partial \rho_{2}} \frac{1-\phi_{1}}{\phi_{1}+\phi_{2}-1} \\
\frac{\partial \bar{f}_{1}}{\partial \theta_{2}} & =\frac{\partial x_{2}}{\partial \theta_{2}} \frac{1-\phi_{1}}{\phi_{1}+\phi_{2}-1} \\
\frac{\partial \bar{f}_{1}}{\partial \sigma_{2}} & =\frac{\partial x_{2}}{\partial \sigma_{2}} \frac{1-\phi_{1}}{\phi_{1}+\phi_{2}-1}
\end{aligned}
$$

whose sign depend on the value of $\phi_{1}$ compared to 1 .

However the sign of $f_{i}$ w.r.t. $\phi_{i}$ remains unspecified as clear looking at the following expression:

$$
\frac{\partial \bar{f}_{1}}{\partial \phi_{1}}=\frac{\phi_{2}}{\phi_{1}+\phi_{2}-1}\left(\frac{\partial x_{1}}{\partial \phi_{1}}-\frac{x_{1}+x_{2}}{\phi_{1}+\phi_{2}-1}\right)
$$

Proof of Proposition 4.2. Since, by assumption $\phi>1 / 2$, the result is straightforward.

Proof of Proposition 4.3. By direct computation we have

$$
\frac{\partial \ln \Lambda}{\partial \phi}=\frac{1}{\phi}-\frac{2}{2 \phi-1}=-\frac{1}{\phi(2 \phi-1)}<0
$$


Proof of Proposition 5.1. The positivity of $\omega$ for all $\phi>\frac{1}{2}$ follows by observing that the limit of $\omega$ when $\phi$ tends to infinity is 0 .

We have

$$
\ln [1+\omega)=-\frac{1}{1-\phi}\left(\ln 2+\phi \ln \left(1-\frac{1}{2 \phi}\right)\right]
$$

By direct computation of the derivative we obtain:

$$
\begin{aligned}
\frac{d \ln (1+\omega)}{d \phi} & =\frac{1}{1-\phi}\left[\frac{1}{1-\phi} \ln \frac{\phi}{2 \phi-1}-\frac{1}{2 \phi-1}\right] \\
& =\frac{1}{1-\phi}\left[\frac{1}{1-\phi} \ln \left(1+\frac{1-\phi}{2 \phi-1}\right)-\frac{1}{2 \phi-1}\right] \\
& <\frac{1}{1-\phi}\left[\frac{1}{1-\phi} \frac{1-\phi}{2 \phi-1}-\frac{1}{2 \phi-1}\right]=0
\end{aligned}
$$

\section{Appendix C. PRoOfs in the $n$-Player CASE}

Optimal response and Nash equilibrium. We assume that the parameters are the same for all players. Suppose first that all players $j \neq i$ play a constant strategy $\Psi j\left(A_{1}, . ., A_{n}\right) \equiv f_{j}$. Then the optimal response of Player $i$ can be found as the solution (in feedback form) of an optimal control whose Bellman equation may be written as:

$$
\begin{aligned}
\rho_{i} \frac{1-\theta_{i}}{1-\phi_{i}} V_{i}\left(A_{1}, \ldots, A_{n}\right)= & \max _{f_{1} \in\left[0,1-\sum_{j \neq i} f_{j}\right]}\left[\frac{\left(f_{i} A_{i}\right)^{1-\phi_{i}}}{1-\phi_{i}} \frac{1}{\left(\left(1-\theta_{i}\right) V_{i}\left(A_{1}, \ldots, A_{n}\right)\right)^{\frac{1-\phi_{i}}{1-\theta_{i}}-1}}+\right. \\
& \left.\left(\sum_{j=1}^{n} \frac{\partial V_{i}}{\partial A_{j}} \alpha_{j}\right)+\frac{1}{2}\left(f_{1}+f_{2}\right)\left\langle\left(\begin{array}{c}
\sigma_{1} \\
\ldots \\
\sigma_{n}
\end{array}\right), H V_{i}\left(\begin{array}{c}
\sigma_{1} \\
\ldots \\
\sigma_{n}
\end{array}\right)\right\rangle\right]
\end{aligned}
$$

where $\langle\cdot, \cdot\rangle$ denotes the scalar product on $\mathbb{R}^{n}$.

We guess and check the following solution: $V_{i}\left(A_{1}, \ldots, A_{n}\right)=\beta_{i} \frac{A_{i}^{1-\theta}}{1-\theta}$ for some positive constant $\beta_{i}$. Then

$$
\frac{\rho}{1-\phi} \beta_{i} A_{i}^{1-\theta}=\max _{f_{i}}\left[\frac{\left(f_{i} A_{i}\right)^{1-\phi}}{1-\phi} \frac{1}{\left(\beta_{i} A_{i}^{1-\theta}\right)^{\frac{1-\phi}{1-\theta}-1}}+\beta_{i} A_{i}^{1-\theta_{1}}\left[\alpha-\theta \frac{\sigma^{2}}{2} \sum_{j=1}^{n} f_{j}\right]\right]
$$

i.e.

$$
\frac{\rho}{1-\phi} \beta_{i} A_{i}^{1-\theta}=\max _{f_{i}}\left[\frac{\left(f_{i} A_{i}\right)^{1-\phi}}{1-\phi} \frac{1}{\left(\beta_{i} A_{i}^{1-\theta}\right)^{\frac{1-\phi}{1-\theta}-1}}+\beta_{i} A_{i}^{1-\theta_{1}}\left[\alpha-\theta \frac{\sigma^{2}}{2} \sum_{j=1}^{n} f_{j}\right]\right]
$$


i.e.

$$
\frac{\rho}{1-\phi}=\max _{f_{i}}\left[\frac{f_{i}^{1-\phi}}{1-\phi} \frac{1}{\beta_{i}^{\frac{1-\phi}{1-\theta}}}+\left[\alpha-\theta \frac{\sigma^{2}}{2} \sum_{j=1}^{n} f_{j}\right]\right]
$$

The maximizer $f_{i}$ on $(0,+\infty)$ (we will check later that point of maximum will be in $\left.\left(0,1-\sum_{j \neq i} f_{j}\right]\right)$ is given by the solution of

$$
\frac{f_{i}^{-\phi}}{\beta_{i}^{\frac{1-\phi}{1-\theta}}}=\theta \frac{\sigma^{2}}{2}
$$

If we replace $\beta_{i}^{\frac{1-\phi}{1-\theta}}$ taken from (50) into (49) we get:

$$
\rho-\alpha(1-\phi)=\theta \frac{\sigma^{2}}{2}\left(\phi f_{i}-(1-\phi) \sum_{j \neq i} f_{j}\right)
$$

i.e.

$$
f_{i}=\frac{x+(1-\phi) \sum_{j \neq i} f_{j}}{\phi}
$$

When all the strategies are symmetric, then

$$
f_{i}=\frac{x}{n \phi-n+1}
$$

Thus using (50),

$$
\frac{\left(\frac{x}{n \phi-n+1}\right)^{-\phi}}{\theta \frac{\sigma^{2}}{2}}=\beta_{i}^{\frac{1-\phi}{1-\theta}}
$$

Per-capita welfare gain and gain from biodiversity conservation. Let us now compute the per-capita welfare gain of moving from Nash equilibrium to optimum, defined as $\omega$ such that

$$
V_{p}\left(\frac{A}{n}\right)=V_{h}((1+\omega) A)
$$

As $V_{p}(A)=\frac{1}{1-\theta} \beta_{p} A^{1-\theta}$ with $\beta_{p}=\left(\theta \frac{\sigma^{2}}{2}\left(f^{*}\right)^{\phi}\right)^{-\frac{1-\theta}{1-\phi}}$

$$
\omega=\left(\frac{1}{n}\left(\frac{n \phi}{n \phi+1-n}\right)^{\phi}\right)^{\frac{1}{1-\phi}}-1 \text {. }
$$


Finally, the per capita welfare gain from biodiversity conservation $\lambda$ is

$$
V_{p}\left(\frac{A}{n}\right)=V_{o a}\left((1+\lambda) \frac{A}{n}\right)
$$

The value of $\lambda$ is the same as in the 2 -player case

$$
\lambda=\left(\frac{\phi f^{*}+(1-\phi)}{f^{* \phi}}\right)^{\frac{1}{1-\phi}}-1 .
$$

\section{ACKNOWLEDGEMENTS}

The work of Giorgio Fabbri is supported by the French National Research Agency in the framework of the "Investissements d'avenir" program (ANR-15IDEX-02) and of the center of excellence LABEX MME-DII (ANR-11-LBX-002301)

Emmanuelle Augeraud-Véron, Gretha, Université de Bordeaux, France

Email address: emmanuelle.augeraud@u-bordeaux.fr

Giorgio Fabbri, Univ. Grenoble Alpes, CNRS, inRa, Grenoble Inp, Gael, Grenoble, France.

Email address: giorgio.fabbri@univ-grenoble-alpes.fr

Katheline Schubert, Paris School of Economics, Université Paris 1 PanthéonSorbonne, France.

Email address: schubert@univ-paris1.fr 